\title{
KAJIAN PEMANFAATAN PASIR LIMBAH TAMBANG PUYA (ZIRCON) DARI DESA TARINGEN, KABUPATEN GUNUNG MAS, SEBAGAI MATERIAL PERKERASAN JALAN PADA CAMPURAN LATASIR
}

\author{
Muhamad Zainul Imron ${ }^{1}$, Salonten ${ }^{2}$ dan Supiyan ${ }^{3}$ \\ ${ }^{123}$ Program Studi Teknik Sipil, Fakultas Teknik, Universitas Palangka Raya \\ E-mail: zainulimron96@ gmail.com ${ }^{1}$, salonten@jts.upr.ac.id ${ }^{2}$,dan \\ supiyan@eng.upr.ac.id ${ }^{3} /$ HP.+6282157338618 1
}

\begin{abstract}
ABSTRAK
Provinsi Kalimantan Tengah merupakan salah satu provinsi terluas di Indonesia, untuk membangun provinsi Kalimantan Tengah ini supaya dalam pembangunannya merata, pemerintah memprioritaskan infrastruktur pembangunan pada bidang perhubungan dengan membuat prasarana transportasi khususnya jalan. Kebutuhan akan material pembangunan jalan terutama pasir semakin meningkat seiring dengan banyaknya pembangunan jalan di Kalimantan Tengah. Karena itu perlu adanya material alternatif pasir yang dapat digunakan untuk kebutuhan pembangunan tersebut. Penelitian ini bertujuan untuk mengetahui apakah pasir dari Desa Taringen, Kabupaten Gunung Mas memenuhi persyaratan atau spesifikasi yang telah ditentukan, sehingga dapat digunakan sebagai agregat dalam campuran $\mathrm{Hot}$ Rolled Sand Sheet (HRSS). Dari hasil penelitian dapat ditarik kesimpulan bahwa, berdasarkan sifat-sifat fisik agregat pasir dari Desa Taringen, Kabupaten Gunung Mas dapat digunakan sebagai agregat pada campuran Lapis Tipis Aspal Pasir (Hot Rolled Sand Sheet). Untuk mengetahui pengaruh pasir, dibuat komposisi campuran dengan 5 (lima) variasi kadar aspal, yaitu komposisi dengan 100\% pasir alam dari Desa Taringen. Berdasarkan hasil tes Marshall dengan komposisi tersebut diperoleh nilai Kadar Aspal Optimum (KAO) sebesar 7,850\%, stabilitas $330 \mathrm{~kg}$, flow 2,9 mm, rongga dalam campuran (VIM) $4,8 \%$, rongga terisi aspal (VFB) $77 \%$ dan hasil bagi Marshall 115,5 kg/mm.

Kata Kunci: Lapis Tipis Aspal Pasir (Hot Rolled Sand Sheet), Parameter Marshall, Kadar Aspal Optimum.
\end{abstract}

\begin{abstract}
Central Kalimantan Province is one of the largest provinces in Indonesia, to develop the province of Central Kalimantan so that in its development evenly distributed, the government prioritizes development infrastructure in the transportation sector by making transportation infrastructure especially roads. The need for road pavement materials, especially sand, is increasing along with the large number of road construction in Central Kalimantan. Therefore, there is a need for alternative sand material that can be used for these development needs. This study aims to find out whether the sand from Taringen Village in Gunung Mas District meets the specified requirements or specifications, so that it can be used as an aggregate in the Hot Rolled Sand Sheet (HRSS) mixture. Mixed planning using the Asphalt Institute method. From the results of the study it can be concluded that based on the physical properties of sand from Taringen Village in Gunung Mas
\end{abstract}


District can be used as an aggregate in a Hot Rolled Sand Sheet. To determine the effect of using sand, two mixed compositions were made with each of 5(five) variations in bitumen content. Composition with a mixture of $100 \%$ natural sand of Taringen Village. Based on the results of the Marshall test with the composition, the optimal asphalt content (KAO) value was 7,850\%, stability was $330 \mathrm{~kg}$, flow was 2,9 mm, cavity in the mixture (VIM) was 4,8\%, cavity filled with asphalt (VFB) $77 \%$ and Marshall quotient was 115,5 kg. $/ \mathrm{mm}$.

Keywords: hot rolled sand sheet, puya mine waste sand, optimum bitumen content.

\section{PENDAHULUAN}

\section{Latar Belakang}

Provinsi Kalimantan Tengah merupakan provinsi yang termasuk dalam provinsi terluas di Indonesia. Untuk membangun provinsi Kalimantan Tengah ini supaya dalam pembangunannya merata, pemerintah memprioritaskan infrastruktur pembangunan pada bidang perhubungan dengan membuat prasarana transportasi khususnya jalan. Kebutuhan akan material pembangunan jalan terutama pasir semakin meningkat seiring dengan banyaknya pembangunan jalan di Kalimantan Tengah. Karena itu perlu adanya material alternatif pasir yang dapat digunakan sebagai bahan campuran pembentuk Lapis Tipis Aspal Pasir (Latasir) atau Hot Rolled Sand Sheet (HRSS). Salah satu alternatif yang dapat dimanfaatkan adalah pasir limbah tambang Puya (Zircon) masyarakat yang terdapat di sepanjang daerah aliran sungai (DAS) Manuhing, khususnya di Desa Taringen Kabupaten Gunung Mas. Pasir limbah tambang puya tersebut merupakan sedimen hasil buangan tambang puya masyarakat di daerah aliran sungai yang berupa pasir yang muncul ke permukaan air sungai yang mengakibatkan terjadinya pendangkalan daerah aliran sungai yang menimbulkan permasalahan bagi lingkungan di daerah tersebut. Kabupaten Gunung Mas secara umum memiliki daerah pemukiman baik di perkotaan maupun diperdesaan, dengan kondisi jalan banyak yang belum diperkeras menggunakan jenis perkerasan yang sesuai untuk dilalui oleh lalu lintas rendah. Jika digunakan Hot Rolled Sand Sheet (HRSS) sebagai campuran perkerasan jalan di Kabupaten Gunung Mas, maka dapat dipertimbangkan untuk memanfaatkan pasir lokal sebagai bahan pembentuk utama dan aspal sebagai bahan pengikat.

\section{Tujuan Penelitian}

Dalam penelitian ini bertujuan untuk mengetahui nilai karakteristik Marshall dari pemakaian pasir yang berasal dari Desa Taringen, Kabupaten Gunung Mas pada masing-masing komposisi pada campuran Hot Rolled Sand Sheet.

\section{METODE PENELITIAN}

\section{1) Umum}


Metode penelitian yang digunakan adalah metode uji laboratorium. Material yang akan digunakan dalam penelitian ini diperiksa terlebih dahulu di laboratorium untuk memperoleh karateristik dari material tersebut.

Data yang digunakan dilaboratorium digunakan untuk perencanaan campuran, selanjutnya dibuat benda uji (briket) sehingga diketahui karakteristik campuran.

\section{2) Lokasi dan Teknik Pengambilan Sampel}

Sampel berupa pasir diambil dari Sapundu I, Desa Taringen, Kecamatan Manuhing, Kabupaten Gunung Mas. Dengan waktu tempuh \pm 3 jam dari Palangka Raya. Sampel diambil secara acak dengan jumlah secukupnya pada lokasi pengambilan sampel tersebut.

\section{3) Metode Pengambilan Data}

Pengambilan data dilakukan dengan membuat briket/benda uji sebanyak 15 buah briket/benda uji untuk mencari (KAO) pada komposisi $100 \%$ pasir alam dari Desa Taringen, dengan 5 variasi kadar aspal, 6\%,6.5\%,7\%,7.5\%,8\% (3 briket/benda uji tiap kadar aspal). Metode pembuatan benda uji briket atau analisis pengujian Marshall mengacu pada prosedur Spesifikasi Bina Marga.

\section{HASIL DAN PEMBAHASAN}

Hasil pemeriksaan gradasi dapat dilihat pada tabel berikut ini.

Tabel 1. Hasil Pemeriksaan Gradasi (Analisa Saringan)

\begin{tabular}{|c|c|c|}
\hline \multicolumn{2}{|c|}{ No. Saringan } & Persentase Lolos Saringan(\%) \\
\hline Inch & $\mathrm{Mm}$ & Pasir Desa Taringen \\
\hline$\# 1 / 2$ & 12.70 & 100,00 \\
\hline$\# 3 / 8$ & 9.50 & 100,00 \\
\hline No. 8 & 2.36 & 100,00 \\
\hline No.200 & 0.075 & 4,24 \\
\hline
\end{tabular}

Sumber: Hasil Pemeriksaan Laboratorium (2021)

Pemeriksaan sifat-sifat fisik agregat yang lain yaitu pemeriksaan berat jenis, penyerapan, sand equivalent dapat dilihat pada tabel berikut.

Tabel 2. Hasil Pemeriksaan Sifat-sifat Fisik Agregat

\begin{tabular}{|l|c|c|}
\hline \multicolumn{1}{|c|}{ Jenis Pemeriksaan } & $\begin{array}{c}\text { Pasir } \\
\text { Desa } \\
\text { Taringen }\end{array}$ & Spesifikasi \\
\hline Berat Jenis (gr/cm $\left.{ }^{3}\right)$ & 2,357 & Min. 2,2 \\
\hline $\begin{array}{l}\text { Berat Jenis (SSD) } \\
\left(\mathrm{gr} / \mathrm{cm}^{2}\right)\end{array}$ & 2,422 & - \\
\hline $\begin{array}{l}\text { Berat Jenis Semu } \\
\left(\mathrm{gr} / \mathrm{cm}^{3}\right)\end{array}$ & 2,521 & - \\
\hline Penyerapan (\%) & 0,028 & Max. 3,0 \\
\hline Sand Equivalent (\%) & 92,88 & Min. 60 \\
\hline
\end{tabular}

Sumber: Hasil Pemeriksaan Laboratorium (2021) 
Perencanaan proporsi campuran menggunakan metode dari spesifikasi Depkimpraswil 2002. Dari perhitungan yang dilakukan kita dapat menentukan perkiraan kadar aspal awal.

Dari proporsi yang telah ditentukan, diperoleh nilai tengah kadar aspal rancangan $7 \%$ yang kemudian diurutkan dua variasi kadar aspal kebawah dan dua variasi kadar aspal ke atas dengan interval 0,5\%. Dari hasil perhitungan perkiraan kadar aspal diperoleh lima variasi kadar aspal yaitu: 6\%, 6,5\%, 7\%, 7,5\%,dan $8 \%$. Persentase terhadap berat total agregat yang digunakan yaitu 1000 gram. Hasil proporsi agregat campuran Latasir (HRSS) dapat dilihat pada tabel berikut ini.

Tabel 3. Proporsi Agregat dalam Campuran

\begin{tabular}{|c|l|c|c|}
\hline No & Jenis Besar Butiran Agregat & $\begin{array}{c}\text { Persentase } \\
\text { Terhadap Total } \\
\text { Agregat }\end{array}$ & $\begin{array}{c}\text { Kadar Aspal } \\
(\%)\end{array}$ \\
\hline 1 & Pasir Desa Taringen & $100 \%$ & $\begin{array}{l}6 \%, 6,5 \%, 7 \%, \\
7,5 \%, 8 \%\end{array}$ \\
\hline
\end{tabular}

Sumber: Hasil Proporsi Kadar Aspal(2021)

Berdasarkan proporsi yang telah ditetapkan, selanjutnya dilakukan perhitungan berat material dan aspal untuk pembuatan benda uji.

Tabel 4. Rencana Berat Material dan Aspal

\begin{tabular}{|c|c|c|c|c|c|c|c|c|c|c|}
\hline \multirow{3}{*}{$\begin{array}{c}\text { Berat } \\
\text { Total } \\
\text { Agregat }\end{array}$} & \multicolumn{10}{|c|}{ Variasi Kadar Aspal } \\
\hline & \multicolumn{2}{|c|}{$6 \%$} & \multicolumn{2}{|c|}{$6,5 \%$} & \multicolumn{2}{|c|}{$7 \%$} & \multicolumn{2}{|c|}{$7,5 \%$} & \multicolumn{2}{|c|}{$8 \%$} \\
\hline & \multicolumn{10}{|c|}{ Berat Kadar Aspal Terhadap Total Campuran } \\
\hline gram & \multicolumn{10}{|c|}{ gram } \\
\hline 1000 & 63,83 & 1063,83 & 69,52 & 1069,52 & 75,23 & 1075,23 & 81,08 & 1081,08 & 86,96 & 1086,96 \\
\hline
\end{tabular}

Sumber: Hasil Perhitungan Rencana Berat Material dan Aspal (2021)

Dari hasil perhitungan berat jenis dan penyerapan terhadap total agregat untuk campuran HRSS diperoleh hasil sebagai berikut.

Tabel 5 Perhitungan Berat Jenis dan Penyerapan terhadap Total Agregat

\begin{tabular}{|c|l|c|}
\hline No & \multicolumn{1}{|c|}{ Pemeriksaan } & $\begin{array}{c}\text { Desa } \\
\text { Taringen }\end{array}$ \\
\hline 1. & Berat Jenis Bulk $(\mathrm{GSB})\left(\mathrm{gram} / \mathrm{cm}^{3}\right)$ & 2,357 \\
2. & Berat Jenis Semu $(\mathrm{GSA})\left(\mathrm{gram} / \mathrm{cm}^{3}\right)$ & 2,422 \\
3. & Berat Jenis Efektif $(\mathrm{GSE})\left(\mathrm{gram} / \mathrm{cm}^{3}\right)$ & 2,389 \\
4. & Penyerapan $(\mathrm{Pba})(\%)$ & 0,628 \\
\hline
\end{tabular}

Sumber: Hasil Perhitungan (2021)

Tabel 6 Hasil Pengujian Marshall untuk Komposisi Pasir Dari Desa Teringen 
JURNAL KACAPURI

JURNAL KEILMUAN TEKNIK SIPIL

Volume 4 Nomor 2 Edisi Desember 2021

\begin{tabular}{|c|c|c|c|c|c|c|}
\hline \multirow{2}{*}{$\begin{array}{c}\text { Kadar } \\
\text { Aspal }(\%)\end{array}$} & $\begin{array}{c}\text { Stabilitas } \\
(\mathrm{kg})\end{array}$ & $\begin{array}{c}\text { Flow } \\
(\mathrm{mm})\end{array}$ & $\begin{array}{c}\text { Berat Isi } \\
\left(\mathrm{gram}_{\mathrm{cm}}\right)^{3}\end{array}$ & $\begin{array}{c}\text { VIM } \\
(\%)\end{array}$ & $\begin{array}{c}\text { VFB } \\
(\%)\end{array}$ & $\begin{array}{c}\text { MQ } \\
(\mathrm{kN} / \mathrm{mm})\end{array}$ \\
\hline 6 & 364,501 & 2,07 & 2,015 & 9,241 & 55,551 & 176,226 \\
\hline 6,5 & 386,592 & 2,23 & 2,018 & 8,541 & 59,515 & 171,310 \\
\hline 7 & 375,016 & 2,47 & 2,028 & 7,466 & 65,436 & 152,439 \\
\hline 7,5 & 343,579 & 2,70 & 2,049 & 5,917 & 72,114 & 127,335 \\
\hline 8 & 320,744 & 3 & 2,073 & 4,215 & 80,082 & 106,830 \\
\hline Spesifikasi & Min. 200 & $2-3$ & - & $3-6$ & Min. 75 & Min. 80 \\
\hline
\end{tabular}

Sumber: Hasil Pengujian Marshall Komposisi Pasir Desa Taringen (2021)

Keterangan: Nilai parameter Marshall yang dicetak merah tidak memenuhi spesifikasi

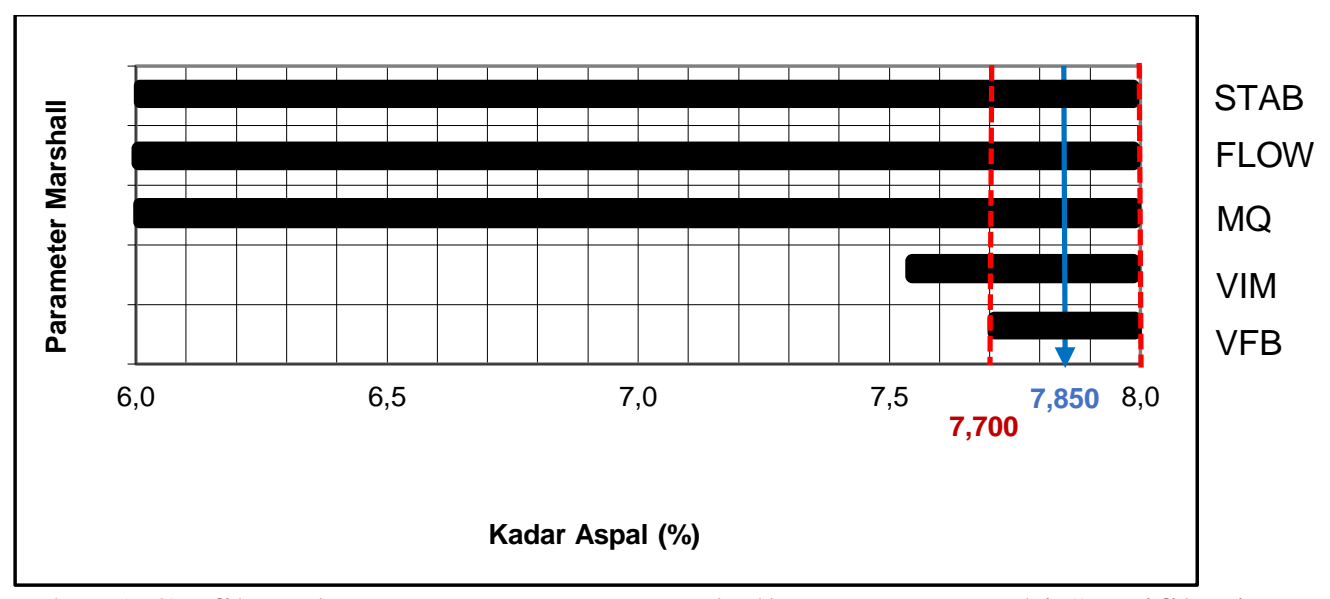

Gambar 1 Grafik Hubungan Parameter Marshall yang memenuhi Spesifikasi terhadap Variasi Kadar Aspal

Nilai parameter Marshall dari masing-masing komposisi berdasarkan nilai kadar aspal optimum (KAO) yang dihasilkan dapat dilihat pada tabel berikut.

Tabel 7 Nilai Parameter Marshall pada Kadar Aspal Optimum

\begin{tabular}{|c|c|c|c|c|c|c|c|}
\hline \multirow{2}{*}{$\begin{array}{c}\text { Komposisi } \\
\text { Campuran }\end{array}$} & $\begin{array}{c}\text { Asal } \\
\text { Material }\end{array}$ & \multirow{2}{*}{$\begin{array}{c}\text { KAO } \\
(\%)\end{array}$} & $\begin{array}{c}\text { Stabilitas } \\
(\mathrm{kg})\end{array}$ & $\begin{array}{c}\text { Flow } \\
(\mathrm{mm})\end{array}$ & $\begin{array}{c}\text { Rongga dalam } \\
\text { Campuran } \\
(\text { VIM })(\%)\end{array}$ & $\begin{array}{c}\text { Rongga Terisi } \\
\text { Aspal (VFB }) \\
(\%)\end{array}$ & $\begin{array}{c}\text { Hasil Bagi } \\
\text { Marshall } \\
(\mathrm{kg} / \mathrm{mm})\end{array}$ \\
\hline pasir alami & $\begin{array}{c}\text { Desa } \\
\text { Taringen }\end{array}$ & 7,850 & 330 & 2,9 & 4,8 & 77,00 & 115,5 \\
\hline Spesifikasi & & & Min. 200 & $2-3$ & $3-6$ & Min. 75 & Min. 80 \\
\hline
\end{tabular}

Sumber: Hasil Perhitungan Marshall 


\section{PENUTUP}

\section{Kesimpulan}

Setelah melalui serangkaian penelitian yang meliputi pemeriksaan bahan/material, perencanaan benda uji dan pengujian benda uji maka dapat ditarik beberapa kesimpulan yaitu:

1. Pemeriksaan sifat-sifat fisik agregat berupa pemeriksaan berat jenis dan penyerapan serta pemeriksaan gradasi, memberikan hasil yang menunjukkan bahwa pasir dari Desa Taringen Kabupaten Gunung Mas dapat digunakan sebagai agregat untuk campuran perkerasan Hot Rolled Sand Sheet.

2. Berdasarkan hubungan parameter Marshall yang memenuhi spesifikasi terhadap kadar aspal pada Komposisi dengan campuran $100 \%$ pasir alami dari Desa Taringen, dengan variasi kadar aspal 6\%,6,5\%, 7\%, 7,5\%, dan $8 \%$ dapat disimpulkan bahwa kadar aspal yang memenuhi spesifikasi yaitu 7,7\% - 8\% sehingga diperoleh KAO sebesar 7,850\%

3. Dilihat dari nilai Kadar Aspal Optimum (KAO) didapat nilai parameter Marshall pada masing-masing komposisi dapat disimpulkan bahwa, pada komposisi dengan campuran $100 \%$ pasir alami Desa Taringen dengan Kadar Aspal Optimum (KAO) sebesar 7,850\% didapat nilai stabilitas $330 \mathrm{~kg}, \quad$ flow 2,9 $\mathrm{mm}$, rongga dalam campuran (VIM) $4,8 \%$, rongga terisi aspal (VFB) $77 \%$ dan hasil bagi Marshall 115,5 kg/mm.

4. Berdasarkan hasil dari pemeriksaan sifat-sifat fisik agregat ukuran gradasi agregat dari Desa Taringen pada saringan No.200 lolos sebanyak 4,24\%. Dilihat dari nilai yang lolos pada saringan No.200 pasir dari Desa Taringen Kabupaten Gunung Mas tergolong dalam Latasir kelas A dengan spesifikasi 4\%-14\%.

5. Dilihat dari sifat-sifat fisik dan parameter Marshall berupa nilai stabilitas dan hasil bagi Marshall penggunaan pasir yang berasal dari Desa Taringen dapat digunakan sebagai agregat untuk campuran perkerasan Hot Rolled Sand Sheet, sedangkan untuk nilai rongga dalam campuran (VIM) sebagian besar cukup tinggi $(>6 \%)$ dan nilai rongga terisi aspal (VFB) kurang dari persyaratan spesifikasi (min. 75\%). Hal ini disebabkan karena pasir yang digunakan baik dari Desa Taringen pada umumnya memiliki filler yang sangat sedikit yaitu 4,24\% (hanya memenuhi batas minimal nilai spesifikasi yaitu 4\%-14\%).

\section{Saran}

1. Dalam pelaksanaan di lapangan komposisi dengan campuran $100 \%$ pasir alami Desa Taringen dapat digunakan, ditinjau dari segi ekonomi dan kekuatan yang dihasilkan, dari segi ekonomi dapat sebagai alternatif penggunaan pasir lokal, juga meningkatkan perekonomian masyarakat sekitar DAS Sungai Manuhing dengan menambang pasir didaerah sekitar DAS, dan dari segi kekuatan komposisi dengan campuran 100\% pasir alami Desa Taringen lebih disarankan untuk digunakan, karena memiliki nilai Kadar Aspal Optimum (KAO) yaitu $7,850 \%$, dan memiliki nilai stabilitas yang cukup tinggi yaitu $330 \mathrm{~kg}$.

2. Penelitian tidak selalu menghasilkan sesuatu yang baik/memenuhi spesifikasi yang telah ditetapkan, tetapi hasil penelitian ini dapat dikaji lebih lanjut dalam hal pemanfaatan sumber daya alam material berupa pasir limbah tambang puya (Zircon) yang berada di Kabupaten Gunung Mas bisa dijadikan dasar untuk penelitian lain dengan tinjauan yang berbeda khususnya dalam teknologi perkerasan jalan. 
3. Dalam penelitian ini pasir dari Desa Taringen memiliki sedikit filler yang hampir mendekati batas minimal nilai filler yang menjadi panduan dalam penelitian. Sehingga diharapkan selanjutnya penelitian ini dapat dilanjutkan dengan melakukan penelitian variasi penambahan filler dengan alternatifalternatif yang dapat menambah nilai filler.

\section{DAFTAR PUSTAKA}

Desriantomy (2007), Penuntun Praktikum Bahan Perkerasan Jalan Raya, Fakultas Teknik Universitas Palangka Raya.

Direktorat Jendral Bina Marga (1983), Pedoman Perencanaan Campuran Beraspal Panas dengan Kepadatan Mutlak, Departemen Pekerjaan Umum, Jakarta.

Direktorat Jendral Bina Marga (2010), Spesifikasi Umum Untuk Pekerjaan Konstruksi Jalan Dan Jembatan, Departemen Pekerjaan Umum, Jakarta.

Direktorat Jendral Bina Marga (2018), Spesifikasi Umum Untuk Pekerjaan Konstruksi Jalan Dan Jembatan, Departemen Pekerjaan Umum, Jakarta.

Mataram, I. N. K., I. N. A. Thanaya, I. G. P. Suparsa, dan L. G. N. Dewi (2015) Kajian Karakteristik Campuran Lapis Tipis Aspal Pasir (Latasir) Kelas A Dengan Crumb Rubber 40 Mesh Sebagai Substitusi Sebagian Agregat Halus, Tugas Akhir, Fakultas Teknik Universitas Udayana, Bali.

Natalia Susanti (2019), Analisis Penggunaan Pasir Limbah Tambang Emas Dari Desa Goha Dan Desa Bawan Kabupaten Pulang Pisau Sebagai Agregat Pada Campuran Hot Rolled Sand Sheet (HRSS), Tugas Akhir, Fakultas Teknik Universitas Palangka Raya, Palangka Raya.

Saodang, H. (2005), Konstruksi Jalan Raya, Nova, Bandung.

Sukirman,S. (1999), Perkerasan Lentur Jalan Raya, Nova, Bandung.

Sukirman, S. (2003), Beton Aspal Campuran Panas, Granit, Jakarta.

Yusnandi Eliason (2009), Pemanfaatan Kerikil Pecah dan Sirtu dari Desa Taringen Sebagai Campuran Pembentuk Lataston Lapis Aus (HRSWearingCourse, Tugas Akhir, Fakultas Teknik Universitas Palangka Raya, Palangka Raya. 